Jpn. J. Human Genet. 30, 213-217, 1985

\title{
TWO SIBLINGS WITH MICROCEPHALY ASSOCIATED WITH CALCIFICATION OF CEREBRAL WHITE MATTER
}

\author{
Takateru IsHITsu, Shoji ChIKazAwa, and Ichiro MATSudA \\ Department of Pediatrics, Kumamoto University \\ Medical School, Kumamoto 860, Japan
}

\begin{abstract}
Summary Two male siblings with microcephaly are described. Cranial CT scanning revealed calcification of cerebral white matter in both cases. The clinical features of these patients were compared with those of other reported cases with microcephaly. Microcephaly with calcification of cerebral white matter had not been previously reported. Therefore, our cases seem to be a previously undescribed genetic disease.
\end{abstract}

\section{INTRODUCTION}

We have examined two male siblings with microcephaly associated with calcification of cerebral white matter. Both children had severe mental retardation and severe spastic quadiplegia. This syndrome appears to be a previously undescribed entity. In this paper, we describe the clinical features of the two siblings.

\section{CASE REPORTS}

Patient 1, a 4-year-1-month-old boy, was born after a normal pregnancy of 38 weeks to a 24-year-old, gravida II, para I mother and a 24-year-old father (Fig. 1A). The parents were unrelated, healthy and of normal intelligence. Patient 2, the 1year-5 month-old brother of Patient 1, was born after a pregnancy of 38 weeks (Fig. 1B). Their birth weights were similar and $2,360 \mathrm{~g}$. Delivery was normal and no resuscitation was required in either case. The first child was a male and normally developed. A female cousin of their mother was diagnosed as cerebral palsy, but did not have microcephaly (Fig. 2). Patients 1 and 2 were referred to our hospital at 5 and 4 months of age, respectively, because of delayed growth and development. Both patients exhibited spastic quadriplegia and epileptic seizures. At age 5 months, Patient 1 weighed $5.07 \mathrm{~kg}(-3.4 \mathrm{SD})$, and the height and head circumference were $57.7 \mathrm{~cm}(-3.3 \mathrm{SD})$ and $36.0 \mathrm{~cm}(-5.1 \mathrm{SD})$, respectively. At the same age, Patient 2 weighed $5.65 \mathrm{~kg}(-2.7 \mathrm{SD})$, and the height and head circumference were $63 \mathrm{~cm}(-1.4$ $\mathrm{SD})$ and $36.0 \mathrm{~cm}(-5.1 \mathrm{SD})$, respectively. At age 4 years- 1 month, Patient 1 weighed 

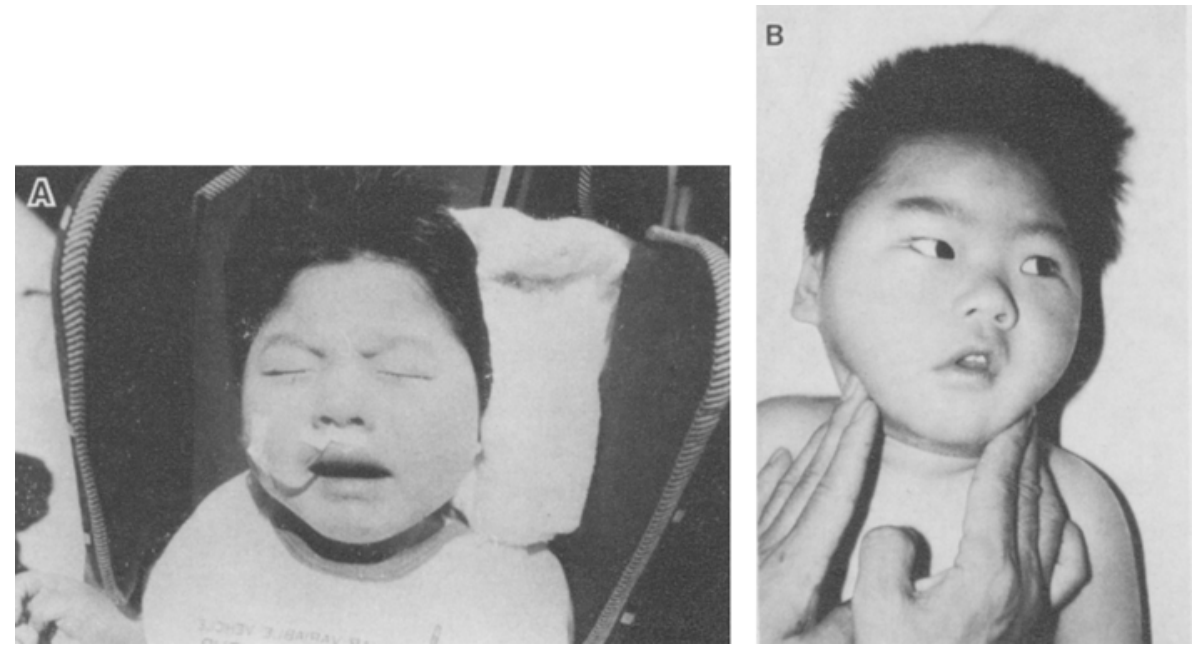

Fig. 1. Case 1 at the age of 3 years (A) and case 2 at the age of 11 months (B). Note the microcephaly.

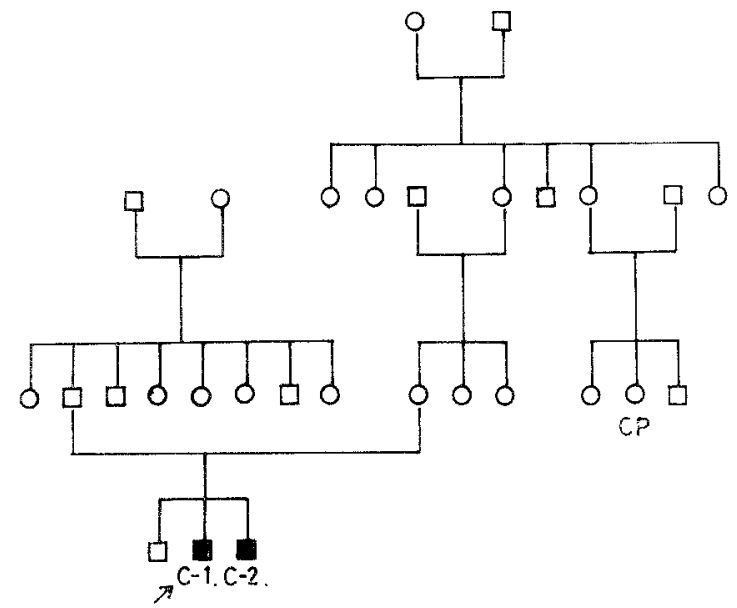

Fig. 2. Pedigree of the family. C-1, case 1 (proband); $\mathrm{C}-2$, case 2 ; CP, case with cerebral palsy.

$10.26 \mathrm{~kg}(-2.9 \mathrm{SD})$, and the height and head circumference were $95.5 \mathrm{~cm}(-1.3 \mathrm{SD})$ and $41 \mathrm{~cm}(-5.5 \mathrm{SD})$, respectively. At 1 year -5 months of age, Patient 2 weighed $7.6 \mathrm{~kg}(-2.7 \mathrm{SD})$, and the height and head circumference were $77.8 \mathrm{~cm}(-1.4 \mathrm{SD})$ and $38.8 \mathrm{~cm}(-5.1 \mathrm{SD})$, respectively. Both patients had slightly large ears but no malformations. On ophthalmological examination, cataracts, chorioretinopathy and micropia were all not seen in both patients. The results of the following laboratory tests were all normal in both cases: peripheral blood count; serum, cerebrospinal 
and urinary amino acid analysis; blood gas analysis; analyses of serum calcium, serum phosphorus, serum alkaline phosphatase, serum total protein, blood sugar, SGOT, SGPT, serum creatinine, serum IPTH, and the calcium to creatinine ratio in urine. The karyotype of both patients was $46 \mathrm{XY}$. The results of a fragile Xchromosome study were negative. EEG examination revealed hypsarrhythmia at 1 year of age in Patient 1, and diffusely slow activity without focal paroxysmal abnormalities at age 6 months in Patient 2. The results of radiological studies of the extremities and vertebrae were normal in both cases. A radiograph of the skull, obtained at age 2 in Patient 1, showed the small size of the cranial vault and intracranial calcification (Fig. 3). Cranial CT scanning revealed that cerebral white

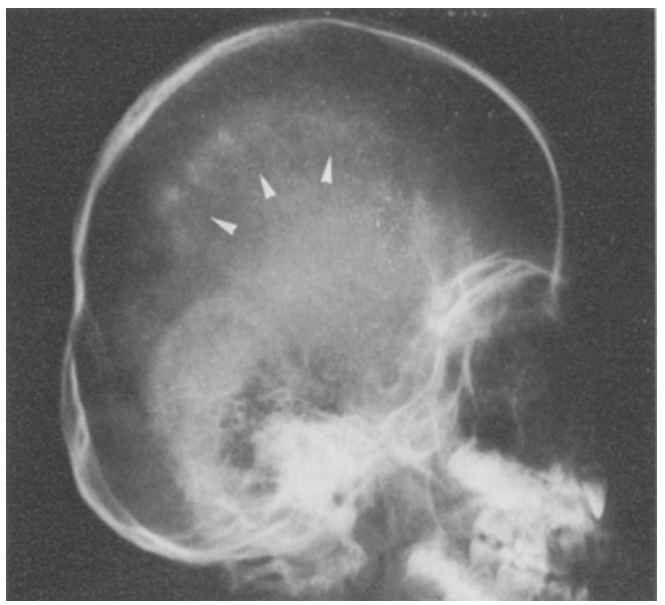

Fig. 3. Lateral skull radiography of case 1. Arrowheads show intracranial calcification.
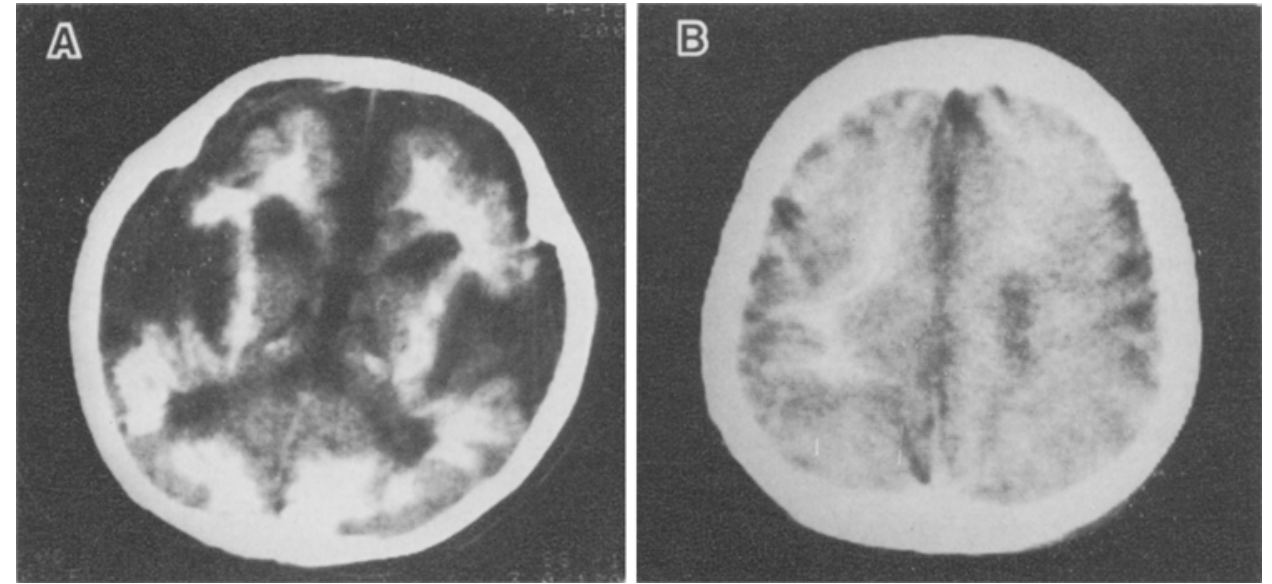

Fig. 4. Cranial CT of case 1 (A) and case 2 (B). Note the calcification of cerebral white matter. 
matter was diffusely calcified, and the cerebral hemispheres were severely atrophic, but the cerebellum was normal (Fig. 4A). Although the grade of calcification was milder, similar radiographic and CT scanning patterns were observed in Patient 2 (Fig. 4B). The antibody titer against toxoplasma, which was measured by the dye test, with the indirect fluorescent system and by the complement fixed test, was negative at age 12 months in Patient 1, at age 4 months in Patient 2, and one year after the last delivery in the mother.

\section{DISCUSSION}

Several cases of inherited microcephaly recorded in the literature showed other associated clinical symptoms: cataracts (Lowry et al., 1971; Neu et al., 1971; Sagarman, 1973; Scott-Emuakpor et al., 1977), retinopathy (Cantu et al., 1977; McKusick et al., 1966), abnormal extremities (Lowry et al., 1971; Ives and Houston, 1980) and abnormalities of bone (Zackai et al., 1972). These abnormalities were absent in our cases. A combination of microcephaly and spastic quadriplegia, similar to our cases, was recorded by Paine (1960), Seemanova et al. (1973), and Bundey and Griffiths (1977). The former two syndromes seemed to be categorized as the same clinical entity and inherited as an X-linked recessive trait, and the latter one was inherited as an autosomal recessive trait. An important difference between our patients and these recorded cases was the presence of intracranial calcification revealed on skull X-ray examination and cranial CT scanning. Dolman and Wright (1978) found intracranial calcification in a patient with microcephaly, in whom, however, the calcification was microscopic and not radiographic, and in addition to microcephaly, cataract, kyphosis and arthrogryposis were observed. These clinical features rather fitted those of Lowey's syndrome.

Cockayne syndrome was the disease associated with microcephaly, growth deficiency, impaired hearing loss, photosensitivity of skin, retinal pigmentation, optic atrophy, cataracts (Cockayne, 1949; Neill and Dingwall, 1950; Macdonald et al., 1960) and intracranial calcification (Land and Nogrady, 1970). The clinical pictures of this syndrome conflicted with our cases. In addition, the lesion of intracranial calcification was basal gangria and cerebellum in Cockayne syndrome (Land and Nogrady, 1970) but the lesion was a cerebral white matter in our cases.

Besides an inherited disease, the possibility of congenital toxoplasmosis should be considered in our cases, since microcephaly, cerebral calcification and psychomotor retardation are common symptoms of this disease (Feldman, 1983). However, the absence of toxoplasmosis antibody as shown by the dye test, with the indirect fluorescent system and by the complement fixed test in both patients and their mother at an appropriate stage, and the absence of chorioretinitis in both patients (which is found in $99 \%$ of congenital toxoplasmosis patients (Feldman, 1983)) seem to rule out this possibility. The mode of cerebral calcification in our case also did not support a diagnosis of congenital toxoplasmosis, for which periventricular calcification 
with ventricular dilatation and cortical calcification are usual findings (Collis and Gromwell, 1980). In our both cases, the calcification was localized in brain white matter. Therefore, the observed syndrome with severe mental retardation, quadriplegia, microcephaly and calcification of brain white matter in these male siblings suggests that this is a previously undescribed genetic disease. Both autosomal recessive and $\mathrm{X}$-linked recessive inheritance are possible at present.

\section{REFERENCES}

Bundey, S. and Griffiths, M.I. 1977. Recurrence risks in families of children with symmetrical spasticity. Develop. Med. Child Neurol. 19: 179-191.

Cantu, J.M., Rojas, J.A., Garcia-Gruz, D., Hernandez, A., Pagan, P., Fragosa, R., and Manzano, C. 1977. Autosomal recessive microcephaly associated with chorioretinopathy. Hum. Genet. 36: $243-247$.

Collis, A.T. and Gromwell, L.D. 1980. Computed tomography in the evaluation of congenital cerebral toxoplasmosis. J. Comput. Assist. Tomogr. 4: 326-329.

Cockayne, E.A. 1949. Dwarfism with retinal atrophy and deafness. Arch. Dis. Child 21: 52.

Dolman, L. and Wright, V.J. 1978. Necropsy of original case of Lowry's syndrome. J. Med. Genet. 15: $227-245$.

Feldman, H.A. 1983. Toxoplasmosis. In Nelson Textbook of Pediatrics, Behrman, R.E. and Vaughan, V.C., III., eds., Sanders, Philadelphia, pp. 847-850.

Ives, E.J. and Houston, C.S. 1980. Autosomal microcephaly and micromelia in Cree Indians.. Am. J. Med. Genet. 7: 351-360.

Land, V.J. and Nogrady, M.B. 1970. Cokayne's syndrome. J. Can. Assoc. Pediatr. 20: 194.

Lowry, R.B., MacLean, R., and McLean, D.M., and Tischer, B. 1971. Cataracts, microcephaly, kyphosis, and limited joint movement in two siblings: A new syndrome. J. Pediatr. 79: 282289.

Macdonald, W.B., Fitch, K.D., and Lewis, I.C. 1960. Cockayne's syndrome. An heredo-familial disorder of growth and development. Pediatrics 25: 997.

McKusick, V.A., Stauffer, M., Knox, D.L., and Clark, D.B. 1966. Chorioretinopathy with hereditary microcephaly. Arch. Ophthal. 75: 597-600.

Neill, C.A. and Dingwall, M.M. 1950. A syndrome resembling progeria: a review of two cases. Arch. Dis. Child 25: 213.

Neu, R.L., Kajii, T., and Gordner, L.I. 1971. A lethal syndrome of microcephaly with multiple congenital anomalies in three siblings. Pediatrics 47: 610-612.

Paine, R.S. 1960. Evaluation of familial biochemically determined mental retardation in children with special reference to aminoaciduria. New Eng. J. Med. 262: 658-665

Sagarman, G.I. 1973. Syndrome of microcephaly, cataracts, kyphosis and joint contractures versus Cockayne's syndrome. J. Pediatr. 82: 351.

Seemanová, E., Lesný, I., Hyánek, J., Brachfeld, K., Rössler, M., and Prošková, M. 1973. XChromosomal recessive microcephaly with epilepsy, spastic tetraplegia and absent abdominal reflexes: new variant of "Paine Syndrome"? Humangenetik 20: 113-117.

Scott-Emuakpor, A.B., Heffelfinger, J., and Higgins, J.V. 1977. A syndrome of microcephaly and cataracts in four siblings. Am. J. Dis. Child 131: 167-169.

Zackai, E.H., Sly, W.S., and McAlister, W.H.K. 1972. Microcephaly, mild mental retardation, short stature, and skeletal amomalies in siblings. Am. J. Dis. Child 124: 111-119. 